\title{
BRASILERAS Y ARGENTINAS, ¿VIDAS PARALELAS? (1870-1930)*
}

\author{
Silvia Cristina Yannoulas**
}

La elaboración de este artículo se basó principalmente en los resultados alcanzados a través de otros estudios de carácter socio-histórico, residiendo su relativa originalidad en la articulación de problemáticas abordadas por otros investigadores e investigadoras del área, así como en la comparación entre la historia de las mujeres en ambos paises considerados. Las fuentes documentales (caracterizadas por "D:" en su citación a lo largo del texto) han sido utilizadas para complementar o apoyar algunas temáticas específicas. En los estudios consultados, los procesos de cambio en la historia de las mujeres y de la relación entre los sexos se encuentran vinculados a la urbanización e industrialización. Por tanto, los procesos a los que haremos referencia no han afectado a toda la población (femenina y masculina) en forma homogénea, y teniendo lugar inicialmente en las ciudades, particularmente en las capitales de provincia o de estado, y principalmente en aquellas situadas más cerca del litoral con mayor contacto con el mundo europeo.

* El presente artículo constituye un subproducto del trabajo de investigación realizado para la Tesis de Doctorado: Eiducar: Una profesión de mujeres? Ia feminizarión del normatismo y de la docencia, Brasil y Argentina, 18701930 (Brasilia, noviembre de 1994).

** Universidad Nacional de Entre Ríos. 


\section{¿Reinas o esclavas del hogar?}

Los estudios históricos sobre la familia señalan un aumento significativo en las tasas de nupcialidad y en la proporción de familias nucleares modernas a partir de las últimas tres décadas del siglo XIX. Ese aumento se relacionó tanto con la estructura de la mano de obra y el tipo de explotación económica (unidad familiar como fuente de plusvalía, a través de la contratación de familias para el trabajo rural e industrial, y a través del trabajo reproductivo realizado por las mujeres en el hogar), con la influencia europea debido a la inmigración, y con factores políticos y simbólicos (legislación sobre familia y códigos civiles, textos escolares, literatura científica positivista y romancista realista y naturalista, periódicos, etc.). El XIX fue un siglo contradictorio para nuestros países. Si por un lado fueron escenario de procesos independentistas (violentos o no) y de la abolición de la esclavitud (femenina y masculina), fueron también escenario de grandes procesos disciplinadores, controladores y discriminadores, que afectaron a la población femenina y masculina y a las familias de los diferentes sectores sociales (aunque en forma diversificada).

Durante la conquista y colonización de los territorios que hoy ocupan Brasil y Argentina, existió también la intencionalidad, por parte de las Coronas y de la Iglesia Católica, de controlar y disciplinar las relaciones entre hombres y mujeres (matrimoniales, sexuales, familiares). Pero las herramientas, mecanismos e instituciones disponibles, es decir, la materialidad de los procesos de control y disciplinamiento de la población, no tenían la potencialidad que se construyó paulatinamente desde mediados del siglo XIX para alcanzar su ápice en las primeras décadas del siglo XX. Así, las descripciones sobre los tipos de unión sexual, conyugal y familiar desde la conquista y hasta mediados del siglo XIX nos muestran un panorama extremadamente variado, que difiere fundamentalmente según la condición social de los hombres y mujeres (esclavos africanos y nativos, hacendados y comerciantes españoles y portugueses, gauchos y sertaneros mestizos o criollos)..$^{(1)}$

Superados los conflictos políticos externos e internos, los nuevos Estados nacionales desarrollaron formas seculares de control social, tales como los registros de nacimiento, matrimonio y defunción, el sistema educativo, el sistema de transporte, el sistema de comunicaciones, los ejércitos y policías, el sistema jurídico-penal. Esta multiplicidad de mecanismos e instituciones propiciaron un disciplinamiento y control de la población argentina y brasileña sin precedentes, legitimados a partir de las ideas modernizantes y cientificistas que defendían el control social en aras del progreso.

Elementos que formaban parte de los intereses de la familia oligárquica (legalidad del matrimonio, ligada al problema de la herencia y por tanto a la virginidad y castidad de las mujeres) pasaron a extenderse paulatinamente al resto de la población. Lo que intentamos sugerir es que en una sociedad republicana, organizada económica y políticamente cultural y jurídicamente, educativa y medicinal- 
mente sobre la base de la universalidad de la familia nuclear, la multiplicidad de formas de vivir y convivir fueron extinguiéndose, en parte porque eran castigadas cuando llevadas a la práctica y en parte por ser cada vez más dificiles de imaginar.

La variedad de tipos de familia y de relación entre los hombres y mujeres fue disminuyendo, tendiendo a una cierta homogeneización mínima que colocó como modelo la familia nuclear moderna. Paralelamente, la diferenciación social no desapareció con esta homogeneización: se hizo más sutil. Este proceso se torna más claro a través de un ejemplo: si bien los nacimientos, matrimonios y defunciones de todas las clases sociales y razas debían ser registrados para tornarse legítimos, lo que los torna en cierta medida homogéneos, esto no tornó a las familias ni a sus integrantes iguales en su importancia social, económica y política.

En el proceso que modela y disciplina a las familias y a sus integrantes, el final del siglo XIX fue crucial: representó la lucha entre los poderes civiles y eclesiásticos por su control. Sin embargo, la legislación republicana de ambos países conservó y agudizó los rasgos principales de las normas eclesiásticas y coloniales: la neta supremacía del hombre y la subordinación de la mujer casada. (2)

En contrapartida, los debates legislativos ponen en evidencia la construcción de una nueva relación de la familia con lo civil: la familia, antigua célula básica de la sociedad (terrena y divina) pasó a ser concebida como la productora de ciudadanos, la base para la defensa de la Patria y la célula básica de la nacionalidad.

Trabajos recientes centrados en el cambio de siglo describen la aparición y el desarrollo del "discurso higienista". Se trata de un discurso elaborado por la medicina social, en el cual la familia era vista como principal razón de los problemas sociales ("enfermedades sociales"). El discurso higienista proponía modelos de comportamiento familiar, basados en las características supuestamente naturales de las mujeres (fragilidad, afectividad, etc.) y de los hombres (vigor, inteligencia, etc.) así como en los sentimientos familiares (amor conyugal, maternal, paternal y filial), para reducir problemas como la mortalidad infantil o la difusión de enfermedades contagiosas.

La medicalización de los problemas sociales no se restringió al ámbito de la medicina. Los discursos políticos e intelectuales de la época también utilizaron categorías y conceptos médicos para proponer soluciones a los conflictos sociales. Las sociedades argentina y brasilera comenzaron a ser "diagnosticadas", y se proponían "remedios" en concordancia (particularmente la "vacuna educativa").

Las mujeres de la élite participaron activamente en la difusión del discurso higienista, principalmente a través de las sociedades de beneficencia, que surgieron, se multiplicaron a lo largo del siglo XIX. Estas sociedades se ocuparon de los problemas sociales denunciados por el discurso higienista, es decir, de la salud y la morada de los indigentes, de la educación de las niñas pobres y huérfanas, de las madres solteras, entre otros ejemplos. Propiciaron a través de sus acciones la maternalización del espacio público, el tratamiento de problemas privados con un 
financiamiento mixto (privado y público), en un espacio que no era ya público ni privado: era social.

El impacto diferencial sobre hombres y mujeres del modelo de familia higiénica puede ser testado a través de las puniciones que ellos y ellas recibian, particularmente la pérdida de libertad en las casas de recogimiento, en el hospicio y en la cárcel: las mujeres eran encerradas cuando no respondían a lo que se esperaba de ellas: ser esposas y madres.

En el caso de encierro en los conventos, se trataba generalmente de mujeres de clase alta. ${ }^{(3)}$ En el caso de los hospicios, si bien el tratamiento que recibían las mujeres en ellos variaba según la condición social, la causa del encierro era la misma, y el trato en el hospicio las igualaba: las internas trabajaban dentro del hospicio en actividades "propias de su condición femenina", cocina, costura, etc., imitando un hogar colectivo, símbolo de orden y salud.(4) Por otra parte, en la literatura y las canciones populares de la época, las mujeres que no obedecian al mandato de una femineidad domesticada dentro de la familia tenían "fines trágicos": madre soltera, hospicio, suicidio.

En el caso del encierro masculino, llama la atención la campaña contra los asesinatos de mujeres en el Brasil, implementada por el Consejo Brasilero de Higiene Social (CBHS) entre 1910 y 1940 . Besse (1989) cuestiona que haya existido un real aumento en la cantidad de asesinatos practicados por hombres como resultado de conflictos amorosos o sexuales durante el período de la campaña, y demuestra que tampoco disminuyeron ni se resolvieron después de implementada. Entonces, por qué esta campaña? Según la autora, los juristas involucrados en ella condenaron los asesinatos de esposas como un resquicio del pasado colonial. Su preocupación estaba menos ligada a la condición y protección de las mujeres que a la idea de una nueva sociedad burguesa donde la familia debía modernizarse, adquiriendo por lo menos una apariencia de igualdad y reciprocidad.

Existe una paradoja en los estudios sobre el pasado de las mujeres en relación a su circulación por el espacio público. Mientras algunos señalan la salida de las mujeres a las calles, su circulación urbana fuera de los límites privados del hogar (Leite \& Massaini; 1989, Newton; s/f), otros destacan la presencia previa de las mujeres en las calles (Dias; 1983 y Figueiredo; 1993). Quizás esta contradicción tenga una explicación en el origen social de las mujeres de referencia: por ejemplo, las mujeres que poblaban la ciudad de Sao Paulo en el texto de Diás son: "brancas pobres, escravas e forras", mientras que las mujeres a las que se refieren Newton o Leite \& Massaini son mujeres de la clase media incipiente y de la élite, que comenzaron a circular en el espacio urbano exterior cuando este quedó "limpio" de la presencia desordenada $\mathrm{e}$ indisciplinada de las otras mujeres y de los hombres.

Los estudios sobre urbanización muestran que, en el imaginario social de fines de siglo XIX, las calles representaban el mundo de la miseria, la suciedad y el caos; un espacio donde se mezclaban y coexistían los trabajadores y trabajadoras con los criminales, rufianes y prostitutas. Estos personajes no fueron excluidos de las calles 
a través de la implementación del discurso higienista: fueron recluidos en calles y barrios específicos, particularmente a través del accionar policial. La presencia desordenada de las prostitutas, por ejemplo, se disciplinó y pautó hasta en los mínimos detalles, a partir de la legislación y de la organización del tráfico de blancas y los prostíbulos modernos, permitiendo a las mujeres "de bien" circular libremente por las calles "limpias e higiénicas" y a los hombres concurrir libremente a los prostíbulos.

La aparición del amor romántico y la posibilidad de selección del candidato para el matrimonio por parte de la interesada, se reflejó en una ampliación de oportunidades para las mujeres de la clase media y alta de circular por el espacio público y social: asistencia al teatro, las visitas programadas, la organización de fiestas y bailes, el casino. ${ }^{(5)}$

El disciplinamiento de las familias y de la población en general fue un proceso paulatino que se registró en ambos países. Dicho proceso encasilló a las mujeres en sus roles de esposas y madres de ciudadanos, y los hombres en sus roles de padres y maridos, sustentadores del hogar. Sin embargo, este encuadramiento de las conductas fue más estricto en el caso de las mujeres, empobreciendo su papel en la sociedad y otorgando menos oportunidades de elección: en tanto los hombres debían sustentar el hogar pero podían hacerlo a través del ejercicio de variadas profesiones, las mujeres debían permanecer en sus roles de esposas y madres.

\section{Educando a las Madres de la Nación}

Durante los primeros dos tercios del siglo XIX coexistieron en el Brasil cuatro tipos de instituciones educativas femeninas: los recogimientos y conventos católicos (frecuentados por todas las clases sociales), las escuelas particulares de profesoras extranjeras (frecuentadas por las hijas de profesionales liberales, pequeños comerciantes y de la elite urbana), los educandarios (destinados a las niñas huérfanas $e$ indigentes) y unas pocas escuelas municipales y provinciales (frecuentadas por niñas humildes). A estos tipos institucionales de educación femenina se sumaban las profesoras extranjeras domiciliares, que instruían a las hijas de la elite residiendo conjuntamente con la familia. Existieron algunas escuelas normales provinciales que admitían muchachas, en clases separadas de los varones, pero en las cuales la calidad de la enseñanza no se equiparaba a la de los bachilleratos, exclusivamente masculinos. ${ }^{(6)}$ Sólo en 1881 se registró la primera matrícula femenina en un curso superior (medicina).

La situación en Argentina no era muy diferente. Las niñas recibían educación elemental en los conventos, escuelas de las asociaciones de beneficencia, escuelas provinciales y municipales, escuelas particulares o con institutrices domiciliares. Algunas muchachas tuvieron acceso a escuelas normales femeninas creadas (y cerradas en sucesivas oportunidades) por congregaciones religiosas y sociedades de 
beneficencia. ${ }^{(7)}$ En 1882 se matricula por primera vez una mujer en los estudios universitarios (también en medicina).

En el último tercio del siglo pasado comenzaron a operarse modificaciones substanciales en lo que se refiere a la educación femenina, tanto en términos cualitativos como en términos cuantitativos. En el primer sentido, se torna frecuente el debate sobre la educación femenina: los educadores, las feministas, los legisladores, algunos presidentes, gobernadores y ministros, se empeñaron en discutir las ventajas y desventajas de brindar educación formal a las niñas y muchachas, y sobre la conveniencia o inconveniencia del sistema coeducativo.

Los liberales se referían sistemáticamente a la posibilidad de mejorar el desempeño de las mujeres como madres y esposas de ciudadanos a través de la educación formal. La oposición de los católicos y conservadores no residía tanto en omitir la educación femenina en sí (dado que la Iglesia Católica había desarrollado instituciones educativas destinadas a las muchachas), sino en la posibilidad de que ésta sea controlada por el Estado, se tornase laica, curricularmente ampliada y coeducativa. El problema no residía en formar mejores esposas y madres: residía en no admitir que esas madres y esposas actuasen por el bien de un Estado Nacional laico.

Cómo podría la educación formal mejorar el desempeño de las futuras madres y esposas de ciudadanos? En varios sentidos: por un lado, la alfabetización de las mujeres permitía difundir el discurso higienista a través de las revistas, de los libros, de la leyes, de los periódicos, de las novelas. Además, la enseñanza de disciplinas específicas para el sexo femenino (higiene y puericultura, culinaria), perfeccionaría y racionalizaría su trabajo doméstico. Y, finalmente, porque la educación transmitiría contenidos morales cívicos, relativos a la nacionalidad. Se actuaría sobre la nacionalidad en dos aspectos: "nacionalizando a las mujeres", es decir, homogeneizando y caracterizando un tipo nacional de mujer, $y$ a la vez transformando a esas mujeres nacionalizadas en vehículos de transmisión de la nacionalidad, en tanto futuras madres de ciudadanos.

Pero también dentro de las filas liberales había conflictos: entre quienes defendían la coeducación y aquellos que querian continuar con una educación separada para las niñas y muchachas. ${ }^{(8)}$ Para algunos, la coeducación era un derivado directo e indiscutible de la obligatoriedad escolar. Otros, aun defendiendo la obligatoriedad escolar y la igualdad de capacidades intelectuales de niños y niñas, reclamaban instituciones separadas según el sexo porque el desarrollo de las capacidades intelectuales y fisicas serían diferentes en cada sexo. Finalmente, había quienes consideraban a la coeducación inconveniente desde el punto de vista moral. ${ }^{(9)}$

El mantenimiento de diferencias curriculares en los estudios elementales de las niñas y de los niños no constituyó una problemática fundamental en el período. Inclusive en las escuelas coeducativas, el curriculum minimo contemplaba diferencias para niñas y niños, referidas a distinto tipo de saberes manuales y ejercicios físicos así como a cantidad de horas diferentes de una misma disciplina destinadas 
a cada sexo. Los propios defensores de la coeducación rescataban estas diferencias como positivas y necesarias dado que, a pesar de reconocerles igualdad de derecho a la educación, uno y otro sexo desempeñarían funciones sociales diferentes.

En el aspecto cuantitativo, el cambio de siglo dio lugar a un proceso de alfabetización y escolaridad primaria crecientes para ambos sexoś, más marcado en el caso argentino que en el brasilero. La diferencia entre alfabetas y alfabetos argentinos tendió a permanecer idéntica, situación que sólo se alteró hacia mediados de nuestro siglo, disminuyendo paulatinamente (LLomovatte; 1989). En el caso brasilero, la diferencia entre alfabetas y alfabetos aumentó, situación que también se alteró hacia mediados de nuestro siglo reduciéndose progresivamente (Rosemberg et al.; 1990).

La diferencia entre la participación femenina y la masculina en la matrícula del nivel primario tendió a permanecer estable en ambos países. Cuando comparadas entre sí, la participación femenina en la matrícula del nivel primario fue levemente superior en Argentina. Por otro lado, en 1929 la mayor parte de la matrícula femenina de ambos paises se concentraba en instituciones de carácter público, aunque en el Brasil la matricula femenina en escuelas privadas es superior (Consejo Nacional de Educación; 1938 y República dos Estados Unidos do Brasil; 1940).

En la educación pos-primaria, el progreso fue más lento. La legislación republicana de ambos países (nacional y estadual o provincial) no impedía formalmente el ingreso de muchachas en los bachilleratos, como a ninguno de los otros niveles educativos. Sin embargo, los padres no las enviaban (por cuestiones económicas o por oposición a la coeducación) o, cuando intentaban hacerlo, eran limitados por las autoridades de las propias instituciones o por los gobernantes. La virada de siglo trajo una novedad en términos cualitativos: la apertura de escuelas profesionales para muchachas y muchachos dentro del ámbito oficial o público, en las cuales la diferencia curricular y de orientación o finalidad también puede ser observada. Primero fueron las Escuelas Normales y las Escuelas de Artes y Oficios (en las últimas décadas del siglo pasado); luego, los cursos de mecanografia y taquigrafia, telegrafia, contabilidad, técnicas de ventas e idiomas extranjeros eran ofrecidos a las muchachas que pretendían trabajar en el sector industrial y de servicios.

Alrededor de 1930 la presencia femenina en la matrícula de las escuelas medias no especializadas era muy baja, comparada con la participación femenina en las escuelas normales. Por motivos similares a los expresados para el nivel secundario, y particularmente por la conexión entre los niveles secundario y superior, hasta 1930 la representación femenina en los cursos de educación superior fue bastante escasa (cfr. República dos Estados Unidos do Brasil; 1940 y Tedesco; 1986).

En Brasil, en 1907 la participación femenina en la matrícula del nivel superior era $1,95 \%$, porcentaje que se elevó a $2,8 \%$ en 1929 . En el mismo año, las mujeres representaban el 4,9\% de los 1677 alumnos que concluyeron estudios superiores 
generales (cfr. República dos Estados Unidos do Brasil; D:1940). En el quinquenio $1900 / 1905$, los títulos otorgados a mujeres por las universidades nacionales argentinas representaban sólo el $0,79 \%$ del total. Este porcentaje se elevó a 9,7\% en el quinquenio 1926/1931 (Maglie y Frinchaboy; 1988).

De esta forma se observa que las políticas públicas en materia educativa favorecieron la alfabetización y la educación elemental de las niñas y muchachas en general, y la educación pos-primaria profesional (particularmente de tipo normalista) para las muchachas de clase media incipiente y humildes. Las niñas y muchachas de clases adineradas continuaron realizando sus estudios en la esfera educativa privada, y algunas de ellas se aventuraron en los estudios superiores oficiales, pero la mayor parte de la población femenina no tuvo acceso a la educación superior. La descripción cuantitativa de la educación femenina en el período señalado se combina muy bien con algunas frases repetidas frecuentemente por políticos y educadores de la época, del estilo: "Generalmente, no es indispensable que las niñas aprendan mucho; pero sí que aprendan bien..." (Torres; D:1890). Las futuras madres y esposas de ciudadanos debían ser educadas, pero no sabias.Muchos niños y jóvenes también fueron discriminados del y dentro del sistema educativo, en función de su condición social. Así, algunas hijas de padres adinerados llegaron a los estudios superiores antes que los hijos de los obreros industriales. También podemos suponer situaciones parecidas según la raza. Sin embargo, si consideramos nin̄os y niñas, muchachas y muchachos en conjunto, podemos afirmar que el sexo femenino fue más discriminado. ${ }^{(10)}$

Hemos descrito la situación educativa femenina en lo que se refiere a la denominada "educación formal". Pero existen otras formas educativas, que escapan a estos moldes. Los aprendizajes en el hogar, en el lugar de trabajo o simplemente en las calles dificilmente son comentados en los textos de historia de la educación. Así, la multiplicidad y pluralidad de los procesos educativos no se encuentran como preocupación (salvo excepciones) entre los historiadores e historiadoras de la educación, lo que perjudica principalmente el conocimiento sobre la educación recibida y brindada por las mujeres y los sectores populares.

Los pocos datos que disponemos generalmente provienen de otras historias temáticas. Por ejemplo, Cárdenas (1986) nos cuenta que la mayor parte de las empleadas domésticas en barrios prestigiosos de Buenos Aires hacia finales del siglo pasado eran alfabetas, y que los saberes relativos a su trabajo eran transmitidos por la propia patrona y por sirvientes más antiguos de la casa. Por otro lado, en las historias de vida recopiladas por Bosi (1979) aparecen relatos sobre el aprendizaje en casa de costura, bordado, cocina por parte de las hijas de sectores populares; sobre el estudio en casa orientado por los hermanos varones mayores de hijas de sectores medios; y sobre el estudio conjunto de anarquistas de ambos sexos en espacios privados. Mott (1992) contrapone el aprendizaje de las parteras "profesionales" (es decir, aquellas que habían realizado el curso específico dictado en la Facultad de Medicina de Río de Janeiro) y las "tradicionales", mayormente mulatas 
y negras pobres que aprendían la profesión de sus madres. Moura (1982) destaca que el trabajo infantil (femenino y masculino) era concebido como forma de profesionalización. Todas estas son piezas de un gran rompecabezas, que precisa ser armado.

\section{Desvios tolerados: trabajadoras}

Los legisladores y sindicalistas de la virada del siglo consagraron la definición de "trabajador" para referirse a los obreros y las obreras industriales. Esta definición tiende trampas aun para los intelectuales, que continúan en muchos casos usando la palabra trabajador para significar obrero industrial, y también para los propios trabajadores de las distintas categorías. Las "dueñas de casa", las maestras, las profesionales liberales, las agricultoras y las prostitutas, aunque por diferentes razones, continúan teniendo dificultades para auto-percibirse y ser percibidas como trabajadoras.

Como eco de esta concepción limitada de trabajadora, son escasos los estudios que intentan reflejar la multiplicidad de trabajos realizados por las mujeres en el pasado, en el campo y en la ciudad, porque la mayoría de los especialistas se ha ocupado de las trabajadoras industriales. Y aun dentro de esta categoría, se han dedicado más al estudio de la explotación de las mujeres en las industrias típicamente femeninas (principalmente textil). Afortunadamente, algunas historiadoras han comenzado a investigar esta diversidad, $y$ han paralelamente extendido el concepto de trabajo. (11)

A pesar de tratarse de censos realizados con categorías diferentes (inclusive para el mismo país, los censos de diferentes años) y muchas limitaciones en cuanto al concepto de trabajo, es posible tener una idea general de la participación femenina en la población económicamente activa (PEA). En nuestro período de análisis, la participación femenina en la PEA disminuyó considerablemente en ambos países. Según Saffioti (1969 b), en 1872 las mujeres representaban el 45,5\% de la población económicamente activa del Brasil, mientras que en 1920 ese porcentaje cayó a 15,3\%. En Argentina, las mujeres representaban el 39\% de la población económicamente activa en 1869, mientras que en 1914 sólo constituían el $21 \%$ (Wainerman y Raijman; 1987). (12)

A su vez, mientras la participación femenina en los sectores primario y secundario tendió a disminuir, sucedió lo contrario en el sector terciario. En el Brasil de 1900, el 91,3\% de la mano de obra empleada en el sector secundario era femenina, porcentaje que cayó a 27,9\% en 1920 (Saffioti; 1969 b); mientras que, en contrapartida, las mujeres representaban el $60,98 \%$ del cuerpo docente en las escuelas primarias en 1907, porcentaje que subió a 75,04\% en 1929 (cfr. República dos Estados Unidos do Brasil; D:1940). En Argentina, Malgesini (1990/3) destaca que el aumento en la categoría de maestras y profesoras constituyó una excepción 
respecto a la evolución de las demás categorías ocupacionales: la participación femenina en el cuerpo docente se quintuplicó en términos absolutos, entre 1895 y 1914.

En el ámbito rural, las mujeres realizaban trabajos dedicados a la producción de alimentos y ropas destinados al consumo familiar y venta en menor escala, y se incorporaban a la tarea agrícola propiamente dicha en las cosechas. En las ciudades, las mujeres fueron obreras de fábricas de tejidos, ropa, cigarrillos, fósforos, sombreros, chocolate, perfumes, cajas, calzados; y, en menor medida, en metalurgia, cerámica y vidrio.

El empleo femenino en las fábricas se caracterizó por la significativa participación de inmigrantes, por su baja proporción en puestos de mando, por su menor retribución salarial, y por su concentración en el sector textil y de confecciones (donde desempeñaban funciones de devanadoras, urdidoras, tejedoras, costureras). Además, es necesario destacar que en muchos casos el trabajo femenino fabril no implicó la separación del hogar y el lugar de trabajo, dado que fue ampliamente utilizado el sistema de trabajo domiciliar, en el cual las mujeres producían en la casa para la fábrica.

En el sector terciario de la economía, las mujeres se incorporaron principalmente como empleadas domésticas, lavanderas y planchadoras, niñeras, institutrices, reposteras, vendedoras, oficinistas, telefonistas, maestras, parteras. Las mujeres de clase media se incorporaron particularmente al sector terciario y al sector informal de la economía a través de trabajos que se realizaban durante media jornada, muchas veces en la propia casa, y permitian "complementar" el presupuesto familiar sin descuidar las funciones de esposa y madre.

La legislación laboral y social, que comenzó a gestarse con el cambio de siglo, se dirigía a las obreras industriales y a los "menores" de ambos sexos, desalentando su ocupación laboral y explicitando como meta específica defender la familia, la maternidad y la infancia. Esta legislación no sólo intentó disciplinar a las obreras y a las familias obreras, sino que también garantizó el espacio de la producción para la mano de obra masculina adulta. También la prensa obrera, anarquista y socialista, señalaba las consecuencias nocivas del trabajo femenino en las fábricas: tuberculosis, prostitución, abandono de menores; y las organizaciones sindicales aconsejaban a sus afiliados que impidiesen el trabajo de hijas y esposas en las fábricas, explicitando además que constituía un peligro para los obreros en términos de competencia en el mercado de trabajo.

El trabajo femenino fabril era descrito como factor de disolución de la familia y de enfermedades que disminuían la capacidad reproductora de las mujeres. Se culpaba a las obreras por la mortalidad infantil, la reducción de los salarios y los desordenes sociales. Este discurso legal y sindical (que también penetró las obras literarias y los libros de lectura), fue mayormente desarrollado por los hombres, pero también las mujeres lo sustentaron. 
La participación femenina en las huelgas ha sido generalmente omitida en las investigaciones sobre el movimiento obrero, a pesar de que existen variadas evidencias documentales. Además, la escasa presencia femenina entre las lideranzas sindicales era fomentada, justificada y explicada por su doble jornada de trabajo (en la fábrica y en el hogar). Tanto Mercado (1988) y Lobato (1993) para el caso argentino, como Pena (1981) y Samara y Matos (1990/3) para el Brasil, rescatan la participación de las mujeres en las luchas gremiales. ${ }^{(13)}$ Estas autoras diferencian la participación femenina y masculina en las huelgas: era más espontánea, circunstancial, efimera y vulnerable en el caso de las mujeres. Participaron principalmente en las huelgas por reducción de salarios, y en menor medida por la reducción de la jornada de trabajo. También reaccionaron por los maltratos corporales, asedio sexual y despidos de las compañeras.

Mucho se esperaba de las argentinas y brasileras de la época: que trabajaran en el hogar y fuera de éste sólo en caso de necesidad (en este caso debían sentirse culpables por abandonar sus dieberes de esposa y madre); que fueran decentes y no comprometiesen el honor y la salud moral familiar; que obedecieran al padre y al marido; que controlaran la reproducción familiar (haciéndose cargo de los futuros ciudadanos, enfermos y ancianos); y, en el caso de las inmigrantes, que se integraran e integrasen a sus familias a la nueva nacionalidad. Y todo esto, en pro del grandioso futuro de la nación.

\section{Otros desvios: feministas}

Desde finales del siglo XIX, se delinearon tres tipos de asociaciones de mujeres: a) asociaciones femeninas para el mejoramiento de la condición femenina (con un carácter básicamente asistencialista y filantrópico); b) asociaciones feministas de lucha por el reconocimiento de los derechos políticos a las mujeres (sufragistas); c) asociaciones feministas clasistas (vinculadas a los movimientos obreros, anarquistas y socialistas). Entre sus integrantes predominaron las mujeres urbanas y letradas de clase alta y media, muchas de ellas maestras y profesionales liberales.

Las publicaciones constituyeron uno de los mecanismos preferenciales en la acción de estas asociaciones, motivo por el cual disponemos hoy de variadas fuentes documentales escritas (artículos periodísticos, colecciones de revistas, libros, ensayos, manifiestos, etc.). ${ }^{(14)}$ Los tres tipos de asociaciones se manifestaron respecto de la condición social, laboral, política y educacional de las mujeres, aunque con distintos puntos de vista. Daremos un ejemplo a través de la problemática educativa.

Las asociaciones femeninas asistencialistas solicitaban más educación para las niñas y las muchachas, con el objetivo de que se tornen mejores esposas y madres. Las asociaciones sufragistas reclamaron por una ampliación de la educación femenina para que las mujeres pudiesen desenvolverse mejor en la vida pública y política nacional. Finalmente, las asociaciones clasistas lucharon por la extensión 
de la educación femenina a todas las clases sociales y en todos los niveles del sistema educativo, como condición de su emancipación económico-social y política.

Los tres tipos de asociación también reclamaron por el ejercicio del magisterio por parte de las mujeres en la educación elemental: las primeras, porque concebían a la docencia como una extensión del cuidado y la educación maternas en el hogar; las segundas, porque veían en la docencia primaria una estrategia para cambiar las relaciones de género, educando a las nuevas generaciones con otros valores culturales; las terceras, porque postulaban la igualdad de la mujer en el desempeño de cualquier profesión.

Todas estas asociaciones concordaban en otorgar derechos civiles a la mujer, manifestándose contra su condición dependiente. Además, concordaban en reclamar más y mejor educación para las mujeres. La unanimidad se quebraba frente a la cuestión de los derechos políticos, y se torna insalvable frente a la denominada "cuestión social", que involucra la problemática del trabajo femenino. Sobre el trabajo femenino, nuestro ejemplo se basará en un hecho argentino que resulta paradigmático, resaltando que los estudios de Hahner (1979), Leite (1984) y Bernardes (1989) nos permiten afirmar que opiniones similares fueron difundidas por las feministas brasileras.

En 1919 Miguel J. Font llevó a cabo la "Encuesta Feminista Argentina", cuyos resultados fueron publicados en dos tomos en el año 1921. Font solicitó la opinión de un grupo de personalidades de la época, feministas y antifeministas de todas las líneas, "... respecto a lo que debe ser en este país el feminismo, en su acción evolutiva y en sus diferenciaciones con el que corresponde a naciones históricamente diferentes." (Recalde; 1988, pág. 20). La temática del trabajo femenino fue la que mayor divergencia registró en las respuestas. Un sector de los encuestados admitió y celebró la irreversible incorporación de las mujeres al mundo laboral; otros encontraron esta incorporación como un hecho lamentable que debería desaparecer. Entre quienes afirmaban que el hogar era el lugar natural de la mujer y los que festejaban su incorporación al trabajo, había posturas intermedias, afirmando que "...la mujer debía seguir siendo 'muy mujer y que los nuevos derechos que se reclamaban no eran incompatibles con la maternidad y el cuidado del hogar." (Recalde; 1988, pág. 21).

Lo que más acercaba a los tres tipos de asociación era la visión higienista sobre el rol que le cabía a las mujeres como esposas y madres, y atacaban o defendían la conquista de derechos políticos o laborales en función de este rol. No escaparon a este eje articulador las feministas clasistas, que actuaron firmemente en la lucha por la sanción de leyes protectoras del trabajo femenino. Es interesante destacar que, en contrapartida, los hombres dificilmente eran definidos en los discursos de cualquier tipo como padres y esposos. Ellos eran referenciados por su clase, su condición económica, su condición social, su profesión o su cargo.

Algunas feministas contemporáneas alegan que la referencia al modelo de esposa y madre higiénica por parte de las feministas clasistas era una cuestión 
estratégica. Sin embargo, no resulta casual la predominancia de médicas entre las feministas universitarias de ambos países, que ayudaron en la difusión del discurso higienista entre el movimiento obrero y el feminista. Más bien nos parece que se trata de un problema foucaultiano del discurso posible y del impensable, dentro de las reglas discursivas en vigencia.. ${ }^{(15)}$

\section{Notas}

(1) En la historia brasilera y argentina colonial no predominó un solo tipo de familia, el patriarcal extenso. Particularmente Correa (1981) desmitificó los procesos de construcción teórica de la historia de la familia, y destacó las limitaciones en el ejercicio del control directo por parte de las autoridades coloniales eclesiásticas y civiles en función de la movilidad espacial de la población y de la extensión de los territorios. (2) Las leyes de matrimonio civil (1889 en Argentina y 1890 en Brasil), así como los códigos civiles (1869 y 1916) consolidaron la organización jerárquica de la familia y la posición jurídica del pater familia. Económicamente, la dependencia femenina se reflejaba en la imposibilidad de gerenciar bienes o de ejercer una profesión. Jurídicamente, las mujeres no podían auto-representarse en procesos legales. Políticamente, no podían votar o ser elegidas (cfr. Guy; 1985, Recalde; 1986, Verucci; 1988).

(3) Soeiro (1978) muestra la fuerte estratificación social y racial en el interior de los conventos bahianos. Origen racial, posición financiera y social eran requisitos para el ingreso de las muchachas como monjas de la más alta categoría (jreiru do véu negro). Al resto de las muchachas admitidas se les asignaba la categoría de legas, siervas o educandas. En estos casos las muchachas no eran recluidas en los conventos por orden familiar. Una situación similar es descrita por Algranti (1993) para el sudeste brasilero.

(4) Analizando las causas de encierro de hombres y mujeres en el Hospicio de Juquery (Sảo Paulo) durante el siglo XIX, Cunha (1989) concluye que las causas de encierro de las mujeres (independencia en las elecciones personales, exceso de trabajo o dedicación en su profesión, hiperexcitación intelectual, orgullo) constituian parámetros de normalidad y salud en los hombres. Precisamente la ausencia de estas cualidades justificaba el encierro de los hombres (dependencia, falta de disposición para el trabajo, incapacidad intelectual).

(5) Siguiendo a D'incao (1989), esta nueva permisividad para con las mujeres de clases medias y altas no significó la supresión de la antigua y estricta vigilancia sobre su sexualidad, sino que la hizo más sutil. El amor romántico contribuyó para ello, estableciendo una mediatización que separaba los cuerpos antes del casamiento. Las personas (particularmente las mujeres) pasaron a auto-vigilarse y auto-controlarse.

(6) Las primeras escuelas normales brasileras fueron fundadas en 1835 en Niterói. 1836 en Bahía, 1845 en Ceará, 1846 en Sao Paulo, 1869 en Porto Alegre. En general, las escuelas normales comenzaron a funcionar sólo para alumnos, incorporando posteriormente a las muchachas, en régimen separado.

(7) Las primeras escuelas normales oficiales argentinas fueron fundadas en 1871 en Paraná (Enure Ríos, coeducativa a partir de 1876), en 1873 en Concepción del Uruguay (Entre Ríos), en 1874 en Buenos Aires (Capital Federal), en 1875 en Tucumán y en 1877 en Rosario. En algunos casos, se fundaron dos escuelas separadas, una para muchachas y otra para muchachos. Posteriormente, estas escuelas se fundieron, principalmente por falta de matricula masculina.(8) En el Brasil, el decreto $\mathrm{N}^{2} 7247$ de 1879 , y en Argentina, la ley $\mathrm{N}^{2} 1420$ de 1884 , recomendaron la coeducación en los primeros grados de las escuelas primarias públicas. Había quienes aceptaban la coeducación pero sólo en los primeros años de escolaridad. Por ejemplo, Barbosa (D:1883) sostenía que la coeducación no podia aplicarse en todos los niveles del sistema educativo por tratarse de un pais tropical y porque sus habitantes aún no estaban 
homogeneizados. Propuso una adaptación paulatina a la coeducación, comenzando por el jardin de infantes y los primeros años de la educación prumaria, bajo la dirección de maestras. Argumentos similares fueron sostenidos por Varela (en Anales te la Eiductición Comün, D:1869, N²1).

(9) Barbosa (D: 1883) se refirió a la cocducación en varios puntos de sus Parereres particularmente en los item sobre la obligatoriedad escolar y sobre la organización pedagógica. En ellos describió y discutió los distintos tupos de argumentación a favor y en contra del sistema coeducativo.

(10) Por ejemplo. en 1872 , el $2.3 \%$ del total de la población masculina y el $1,1 \%$ de la femenina estaba matriculada en la escuela primaria en el Brasil. En el mismo año, el $0.2 \%$ de los brasileros y el $0,05 \%$ de las brasileras cursaba el nivel secundario (Pena; 1981). Cuanto más alto el nivel educativo considerado. mayor la diferencia registrada entre porcentajes femeninos y masculinos. La situación se repite para Argentina.

(11) Por ejemplo. Pena (1981) se reficre a los distintos trabajos femeninos domiciliares; Dias (1984) destaca las múltiples tareas de las mujeres de sectores populares, particularmente en las calles; Rago (1985) se ocupa de las prostitutas; Cárdenas (1986) describe la situación de las empleadas domésticas; Mercado (1988) se refiere a la movilización gremial de las obreras industriales; Pagani y Alcaraz (1988) comentan las condiciones laborales de las nodrizas; Samara y Matos $(1990 / 3)$ tratan el trabajo femenino en el sector informa:, Frederick (1993) se ocupa de las escritoras, periodistas y traductoras.

(12) Estos datos reflejan parcialmente la realidad. Si bien es cierto que muchas mujeres dejaron el mercado de trabajo. también es cierto que muchas no se declaraban o no eran registradas como trabajadoras (porque realizaban trabajo doméstico, porque fabricaban dulces $\mathbf{u}$ otros productos lucgo comercializados por sus esposos e hijos varones, porque en algunas fábricas paulistas se comenzó a contratar familias y a registrar como trabajador sólo al jefe de familia, entre otros motivos). Para una mayor comprensión de la subnumeración de la contribución económica de las mujeres en América Launa, véase Wainerman y Moreno (1986). (13) Por ejemplo, Mercado (1988) cuenta las diversas huelgas organizadas y llevadas a cabo por las tabacaleras, las alpargateras y las fosforeras entre 1904 y 1906, que posteriormente lograron el apoyo de las centrales de trabajadores (cuyos dirigentes eran todos hombres). Pena (1981) se refiere a las huelguistas brasileras, destacando que en 1906 y 1907 pararon en las fábricas de todo el pais por la disminución de la jornada de trabajo.(14) En la segunda mitad del siglo XIX surgieron una multiplicidad de periódicos dirigidos y editados exclusivamente por mujeres, hecho inédito en la historia de ambos países. Estas fuentes han sido analizadas por diversas especialistas - brasileras. argentinas y estadounidenses-, entre las que se destacan Little (1978), Feijeo (1978), Hahner (1979), Leite (1984), Bicalho (1989), Bernardes (1989) y Frederick (1993). Hahner (1979) y Frederick (1993) destacan que estas publicaciones no han sido incorporadas a la reflexión académica sobre la producción periodistica en Brasil y Argentina.

(15) De ninguna manera desmerecemos el espiritu y las acciones desarrolladas por las feministas del pasado, que frente a la constante ridiculización y oposición (masculina y femenina) persistieron en la lucha contra la discriminación sexual y por la emancipación de las mujeres. Nuestra intención es señalar las formas en que el movimiento feminista incorporó el discurso hegemónico de la madre cducadora en función de una visión higienista. Una de ellas fue, evidentemente, los estudios universitarios en Medicina. 


\section{REFERENCIAS BIBLIOGRÁFICAS}

Siempre que posible, colocamos el nombre de pila del autor o autora, a fin de identificar su sexo. Por otro lado, indicamos entre paréntesis la fecha de edición/producción original de la obra, a fin de localizarla cronológicamente.

Leila M. Algranti (1993), Honradas e devotas: mulheres da colômia. Condiça feminina nos conventos $e$ recolhimentes do Sudeste do Brasil, I750-1822, Edunb/José Olympio, Brasília, 1993.

Cybele C. de Almeida (1991), “O magistério feminino laico no século XIX", en Teoria E̋' Educasão, № 4. Porto Alegre, 1991, págs. 159-171.

Benedict Anderson, (1977), Nucuo e consciênria nurional, Atica, São Paulo, 1989.

Ana M. Araujo (1985), "Hacia una identidad latinoamericana. Los movimientos de mujeres en Europa y en América Latina”, en Nueva Soriedad, № 78, Caracas, julio/agosto 1985, págs. 89-92.

Rosa M.B. de Araujo (1992), A sorializansao da mulher no Rio Reprublicuno, ANPOCS, Caxambú, 1992, mimeo. Carmen Barroso (1982), Mulher, sociedude e estado no Brasil, Brasiliense/UNICEF, São Paulo, 1982.

Maria T.C.C. Bernardes (1989), Mulheres de ontem? Rio de faneiro - Século XIX, Queiroz, São Paulo, 1989.

Maria T.C.C. Bernardes (1989), "República Brasileira em Jornais Femininos da Epoca (1889-1890)", en Cadernes de Pesquisa, N 71, São Paulo, noviembre 1989, págs. 20-27.

Susan K. Besse (1989), "Crimes passionais: a campanha contra os assassinatos de mulheres no Brasil: 1910-1940", en Revisun Brasilezru de Histónu, № 18, São Paulo, 1989, págs. 181-197.

Maria F.B. Bicalho (1989), "O bello sexo: imprensa e identidade feminina no Rio de Janeiro em fins do século XIX e início do século XX”, en Albertina de C. Costa \& Cristina Bruschini (orgs.), Rebeldia e submissão. Estudios solve condição feminina, Fundação Chagas/Vértice, São Paulo, 1989, págs. 79-99.

Eva A. Blay (1969), Mulher, Escola e Profissão: Um estudo do ginaisio industrial feminino na cidade de Säo Paulo, CERU/FFLCH-USP, São Paulo, 1981.

Eclea Bosi (1979), Memoria e Sociedtate. Lembrancas de velhos, Queiroz/EDUSP, São Paulo, 1988.

Cecilia Braslavsky (1984), Mujer y Educariôn. Desiguatdades educativas en Aménica Latina y el Caribe, UNESCO, Santiago de Chile, 1984.

Isabel L Cárdenas (1986), El servicio doméstico en barios prestigiosos de Buenos Aires (1895-1985), Búsqueda, Buenos Aires, 1986.

Mariza Correa (1981), "Repensando a família pauriarcal brasileira", Cadernos de Pesquisı, N² 37, São Paulo. mayo 1981, págs. 34 .

Maria C.P. Cunha (1989), "Loucura, gênero feminino: as mulheres do Juquery na São Paulo do início do século XX”, Revista Brasilenra de Histónún N²18, Sảo Paulo, 1989, págs. 121-144.

Zeila de B.F. Demartini \& Fátima F. Antunes (1993), "Magistério primário: profissao feminina, carreira masculina", Cadernos de Pesquisa, № 86, Sao Paulo, agosto 1993, págs. 5-14.

Maria O.L. da S. Dias (1983), "Mulheres sem História", Revista de Histónia, N 114, Sâo Paulo, junio/julio 1983, págs. 30-45.

Maria O.L. da S. Dias (1984), Quotidiano e Poter em São Puulo, Brasiliense, São Paulo.

Maria O. L. da S. Dias (1993), "A condição feminina e suas historicidades", Listurtos Féministas, N² 2, Rio de Janeiro, 1993, págs. 481-485.

Maria A. D'incao (1989), “O amor romántico e a família burguesa”, en Maria A. D'incao (org.) (1989), Amor e familia no Bresilh, Contexto, Sảo Paulo, págs. 57-71.

Tulio Halperín Donghi (1986), Historia contemporínea de América Latine, Alianza, Buenos Aires,

Nélida Eiros (1990), "Mujer y trabajo: una perspectiva historiográfica”, en Jorge N. Sanchez (ed.) (1990), Historia de la mujer y la familia, Editora Nacional, Quito, 1991, págs. 105-131.

Magali Engel (1988), Meretrizes e doutores. Saber médiou e prostituiç̄o no Rio de Janeiro (1840-1890), Brasiliense, Sào Paulo. 
Magali G. Engel (1989), “Imagens femininas em romances naturalistas brasileiros (1881-1903)”, Revista Brasileira de Históna, $\mathrm{N}^{2} 18$, Sao Paulo, 1989, págs. 237-258.

Maria del C. Feijoo (1978), "Las luchas feministas", en Torto es Historia, N 128, Buenos Aires, enero 1978, págs. 7-23.

Luciano Figueiredo (1993), O avesso da memória. Cotidiano e trabalho da mulher em Minas Gerais no século XVIII, Edunb/José Olympio, Brasília.

Bonnie Frederick (comp.) (1993), La pluma y ta aguja: las escritoras de la generación del '80, Feminaria, Buenos Aires.

Guillermo Furlong (1951), La cultura femenina en la época colomial, Kapelusz, Buenos Aires.

Lucia Galvez (1990), Mujeres de la conquisth, Planeta, Buenos Aires, 1992.

Juan C. Garavaglia y Raúl Fradkin (1992), Vuda cotidiana. Hombres y mujeres de la colonia, Sudamericana, Buenos Aires.

Gino Germani (1955), Estructura social de la Argentina, Raigal, Buenos Aires.

Eliana M. Goldchmit (1992), "Virtude e pecado: sexualidade em São Paulo colonial", en Albertina de O. Costa \& Cristina Bruschini (org.) (1992), Entre a virlude e o pecado, Rosa dos Tempos/Fundación Carlos Chagas, Rio de Janeiro, págs. 15-36.

Emily Grosholz (1988), "Mulheres, história e deliberação práctica" en Mary Mc.C. Gergen (ed.) (1988), $O$ pensamento feminista e a esirutura do conhecimento, Rosa dos Tempos/EdunB, Brasilia, 1993, págs. 199-208.

Donna J. Guy (1985), "Familias de clase baja, mujeres y el derecho: Argentina, siglo XIX", en Dora Barrancos (comp.) (1993), Historia y génern, CEAL, Buenos Aires, págs. $43-64$.

June E. Hahner (1979), A mulher brasileira e suas lulas soriais e políticas. 1850-1937, Editora Brasiliense, São Paulo, 1981.

June E. Hahner (1992), "Educação e ideologia: profissionais liberais na América Latina no século XIX", en Estudos Feministas, № 3, São Paulo, 1994, págs. 52-64.

Maria de L.M. Haidar (1972), O ensino secundáno no Impénio Brasileiro, EDUSP/Grijalbo, São Paulo.

Eric Hobsbawn \& T. Ranger (ed.) (1983), The invention of tradition, Cambridge University Press, Cambridge.

Miriam L.M. Leite (org.) (1981), A condičão feminina no Rio de Janeiro. Século XIX, HUCITEC/Pró-Memória/Instituto Nacional do Livro, Sảo Paulo, 1993.

Miriam L.M. Leite (1984), Outra face do feminismo: Maria Lacer da de Moura, Atica, São Paulo.

Míriam M. Leite \& Márcia I. Massaini (1989), "Representaçôes do amor e da família”, en Maria A. D'incao (org.) (1989), Amor e família no Brusil, Contexto, São Paulo, págs. 72-87.

Míriam L.M. Leite (1990), "Uma construção enviesada: a mulher e o nacionalismo", en Ciência e Cultura, № 42, São Paulo, febrero 1990, págs. 144-149.

Helena Lewin (1980), "Educação e força de trabalho feminina no Brasil", en Cadernos de Pesquisa, N 32 , São Paulo, febrero 1980, págs. 45-59.

Cynthia J. Little (1978), "Educación, filantropía y feminismo: partes integrantes de la femeneidad argentina, 1860-1926", en Asunción Lavrin (comp.) (1985), Las mujeres latinoamericanas. Perspectivas histónicas, FCE, México, págs. 271-292.

Silvia LLomovatte (1989), Analfabetismo y analfabetos en Argentina, FLACSO/Min̄o y Dávila, Buenos Aires.

Mirta Z. Lobato (1993), "Mujeres obreras, protesta y acción gremial en la Argentina”, en Dora Barrancos (comp.) (1993), Historia y género, CEAL, Buenos Aires, págs. 65-97.

Guacira L. Louro (1989), "Magistério de 1ro. grau: um trabalho de mulher", en Educașìo e Realidade, vol. 14, N² 2, Porto Alegre, julio/diciembre 1989, págs. 31-39.

Ana M.B. de M. Magaldi (1992), "Mulheres no mundo da casa: imagens femininas nos romances de Machado de Assis e Aluizio Azevedo", en Albertina de O. Costa \& Cristina Bruschini (org.) (1992), Entre a virtude e o pecudo, Rosa dos Tempos/Fundación Carlos Chagas, Rio de Janeiro, págs. 57-88.

Graciela Maglie y Mónica G. Frinchaboy (1988), Süluarion educativa de las mujeres en Argentine, Subsecretaría de la Mujer de la Nación/UNICEF, Buenos Aires. 
Graciela Malgesini (1990/3), "Las mujeres en la construcción de la Argentina en el siglo XIX", en Georges Duby y Michelle Perrot (1990/3), Historia de las mujeres, Taurus, Madrid, 1993, vol. 4, págs. 653-667.

Maria I.S. de Matos (1994), Delineando corpos. As representasoes do feminino e do masculino no discurso médico. São Puulo, 1890-1930, Núcleo de Estudos da Mulher/PUC, São Paulo, mimeo.

Matilde A. Mercado (1988), La primera ley de trabrijo femenino. La "mujer obrera"( 1890 -1910). CEAL, Buenos Aires.

Ricardo R. Molas (1984), Divorcio y familia trudirzonal, CEAL, Buenos Aires.

Graciela Morgade (1992), "La docencia para las mujeres: una alternativa contradictoria en el camino hacia los saberes "legitimos", en Propruestu liducativa, N² 7, octubre 1992, Buenos Aires, págs. 53-62.

Graciela Morgade (1993), "Quiénes fueron las primeras maestras?”, en Revista del Instiluto de Investigaciones en Ciencias de la Eduración, № 2, Buenos Aires, julio 1993, págs. 52-61.

Maria L. de B. Mott (1992), "Parteiras no século XIX: Mme. Durocher e sua época", en Albertina de O. Costa \& Cristina Bruschini (org.) (1992), Fintre a virtude e o pecado, Rosa dos Tempos/Fundación Carlos Chagas, Rio de Janeiro, págs. 37-56.

Esmeralda B.B. de Moura (1982), Mulheres e menones no trabalho industrat: os fatores sexo e idade na dinimica do capital, Vozes, Petrópolis.

Esmeralda B. B. de Moura (1989), "Além da indústria têxtil: o trabalho feminino em atividades 'masculinas", en Revista Brasileira de Histônia, vol. 9, N²18, 1989, Sāo Paulo, págs. 83-98.

Lily S. de Newton (s/f), Las argentinas de ayer a hom, Zanetti, Buenos Aires, s/f.

Lily S. de Newton (1985), "Incorporación de la mujer al periodismo en la Argentina", en Juana A. Arancibia (ed.) (1985), Evaluación de la literalura femenina de Latinoumérica, siglo XX: II Simposio Internarional de Literatura, Instituto Literario y Cultural Hispánico, San José de Costa Rica, págs. 263-270.

Estela Pagani y Maria V.Alcaraz (1988), Las nosirizas en Buenos Aires. Un estudio histónico (1880-1940), CEAL, Buenos Aires.

Maria V.J. Pena (1981), Mulheres e trabalhadomis. Presenca feminina na constiluicuio do sistema fabril, Paze Terra, Rio de Janeiro.

Tirsa R. Perez (1979), “A instrução secundria feminina no Brasil: 1889-1930", en Didáticu, vol. 15, 1979, Sảo Paulo, págs. 35-43.

Mary del Priore (1993). Ao sul do corpo. Condîầo feminina, maternidades e mentatidades no Brasil Colônia, José Olympio Ed./Edunb, Rio de Janeiro.

Margareth Rago (1985), Do caburet ao lar. A utopia da cidade disciplinar. Brasil 1890-1930, Paz e Terra, Rio de Janeiro.

Margareth Rago (1989), "Nos bastidores da imigraçâo: o tráfico das escravas brancas"., en Revistı Brasileira de Históniç, vol. 9, N 18, 1989. São Paulo, págs. 145-180.

Héctor Recalde (1986), Matrimonio civil y divarcio, CEAL, Buenos Aires.

Héctor Recalde (1988), Mujer, condiciomes de vida, de trabijo y salud, CEAL, Buenos Aires.

Maria C.D. Reis (1991), Tessitura de destinos (mulher e educușâo: São Paulo, 1910/20/30), EDUC, São Paulo, 1993.

Fúlvia Rosemberg et all (1990), Mulher e educasùo formal no Brasil: estudo da arte e bibliografia, REDUC/INEP, Brasilia.

Heleieth I.B. Saffioti (1969a), A mulher na sociednde de classes. Mito e venlidade, Vozes, Petrópolis, 1976.

Heleieth I.B. Saffioti (1969b), Profissionalizaç̃o feminina: professônzs primainas e opercinas, Faculdade de Filosofia, Ciências e Letras de Araraquara, Araraquara.

Eni de M. Samara (1989), As mulheres, o poster e a familin. Säo Paulo, século XIX, Marco Zero/Secretaria de Estado da Cultura de São Paulo.

Eni de M. Samara y Horacio Gutierrez (1990/3), "Mujeres esclavas en el Brasil del siglo XIX", en Georges Duby y Michelle Perrot (1990/3), Historia de lus mujeres, Taurus, Madrid, 1993, vol. 4, págs. 643-652.

Eni de M. Samara y Maria I.S. de Matos (1990/3), "Manos femeninas. Trabajo y resistencia de las mujeres brasileñas 1890-1920", en Georges Duby y Michelle Perrot (1990/3), Historia de las mujerrs, Taurus. Madrid, 1993, vol. 5, págs. 709-717. 
Luisa B. de Sanguinetti (1940), La instructión fmimaria durante la dominarión española en el lemritonio que forma actualmente la Repriblea Argentina, Consejo Nacional de Edecación, Buenos Aires.

Maria B.N. da Silva (1977), "Educação feminina e educação masculina no Brasil colonial", en Revista de Histórin, vol. LV, No 109, Rio de janeiro, enero/marzo 1977, págs. 149-164.

Susan A. Soeiro (1978), “Las órdenes femeninas en Bahia, Brasil, durante la Colonia: implicaciones económicas, sociales y demográficas, 1677-1800", en Asunción Lavrin (comp.) (1985). Las mujeres latinocamericunas. Perspertivas hislóricas, FCE, México, págs. 202-228.

Raquel Soihet (1989a), "Mulheres ousadas e apaixonadas. Uma investigação em processos criminais cariocas (1890-1930)". en Rerrsta Brasilezira de Históna, vol. 9. № 18, 1989, Sāo Paulo, págs. 199-216.

Rachel Soihet (1989b), Condicrio feminina e formas de violência. Mutheres pobres e ordem urbana 1890-1920, Forense Universitária, Rio Janeiro.

Verena Stolke (s/d), "A família que nào é sagrada (sistemas de trabalho e estrutura familiar: o caso das facendas de café em São Paulo", en Maria S.K. de Almeida (s/d), Colcha de Retalhas. Estudos solre a familia no Brassal, Brasiliense, São Paulo, s/d, págs. 39-90.

Juan C. Tedesco (1986), Educación y sociedid en ta Argentina 1880-1945, Solar, Buenos Aires.

Florisa Verucci (1988), "Um novo estatuto civil para a mulher", enNanci V. de Carvalho (org.) (1988), A condiçào femininu, Vértice, Sảo Paulo, págs. 52-64.

Luis Vitale (1987), La mitad invisible de la historia, Sudamericana/Planeta, Buenos Aires.

Catalina Wainerman y Marysa Navarro (1979), Et trubujo de la mujer en ta Angentina: un anuilisis preliminar de las ideas dominamles en las primeras décadias del siglo XX, CENEP, Buenos Aires. Catalina Wainerman y Martín Moreno (1986). "Hacia el reconocimiento censal de las mujeres trabajadoras", en Cecilia Blondet (comp.) (1987), Mujer y sociedtad. Perspectivas metodologicas, Instituto de Estudios Peruanos/Fundación Friedrich Naumann, Lima, págs. 51-103.

Catalina Wainerman y Rebeca B. de Raijmann (1987), Sexismo on los libros de lecturn de la escuela primaria, IDES, Buenos Aires.

\section{REFERENCIAS DOCUMENTALES (D:)}

Anules de la Educacion Comün, (1866-1875), Buenos Aires.

A Austregesilo (1923). Pefil da mulher lrasileira (eslkộo arêra do jeminismo no Brasil), Livraria Francisco Alves, Rio de Janeiro.

Rui Barbosa (1883). Reforma do linsino Primaino e Vírias Instituifties Complementares da Instrucäo Pública. Fundação Casa de Rui Barbosa/Fundação Cultural do Estado da Bahia/Conselho Estadual de Educação, Rio de Janciro, 1982.

Ina von Binzer (1887). Os meus romanos. Alegrias e tristezas de uma educadora alema no Brasil, Paz e Terra, Sâo Paulo, 1991.

Carlos O. Bunge (1927), Lisludies perdagógicos, Espasa-Calpe, Madrid.

Adolfo Caminha (1893), A normalistu, Atica, São Paulo, 1985.

Tito L. de Castro (1893), A mulher e a sociogenia, Livraria Francisco Alves, Rio de Janeiro.

Consejo Nacional de Educación (1938), Cincuentenurio de la ley 1420, Buenos Aires.

El Monitor de la Eiducurion Común (1881-1931), Consejo Nacional de Educación, Buenos Aires.

Nisia Floresta (1853), Opüsrulo humaniláno. Cortez/INEP, São Paulo, 1989.

Manuel Gálvez (1914), La maestra nomal, Losada, Buenos Aires, 1964.

Manuel Gälvez (1920), Nacha Regules, Losada, Buenos Aires, 1960.

Thomas W. Hichliff (1863), Viaje al Platn en 1861, Hachette, Buenos Aires, 1955. 
Jennie E. Howard (1931), In distant climes and other years. The American Press, Buenos Aires.

IBGE (1941), Sénies estatisticas retraspertivas. Vol. 1. Reppertónio estatistico do Brasil. Quadros retrospertivos, Rio de Janeiro, s/d.

IBGE (1990), Estutísticas histónicus do Brasil. Sérieseconômicas, demogräficas e sociais de 1550 a 1988, Rio de Janeiro.

Elvira López (1901), El movimiento feministh, UBA, Buenos Aires, Tesis de Doctorado.

Victoria Ocampo (1991), Autobrogrıfia, Alianza, Madrid.

Afrânio Peixoto (1923), Ensinar a ensinat. linsaios de Pedagogia aplicada di educașäo nacionah, Livraria Francisco Alves, Rio de Janeiro.

Afrânio Peixoto (1936), A educasûo da mulher, Ed. Nacional, São Paulo, 1936.

República Argentina (1910), Investigarión solne el estado de la Enseñanza Serundaria Buenos Aires.

República dos Estados Unidos do Brasil (1940), Anuánio do Ministénio da Educascāo e Saúde Pública, Imprensa Nacional, Rio de Janeiro.

Domingo F. Sarmiento (1959), Textos fundamentules, Compañia General Fabril Editora, Buenos Aires. José M. Torres (1890), Vanos asuntos de política doméstica y educación, Estrada y Cía, Buenos Aires. J. Verissimo (1890), A educacĩo narionah L. Francisco Alves, Rio de Janeiro, 1906. 